\title{
Comparative Study of the Efficacy of L-Tryptophan Nanoparticles on Motor and Cognitive Behavior in an Alzheimer's Experimental Model
}

Meirielly Furmann ${ }^{1}$

https://orcid.org/0000-0002-8045-5755

Andressa Leticia Miri ${ }^{2}$

https://orcid.org/0000-0002-9057-5339

Andressa Panegalli Hosni ${ }^{3}$

https://orcid.org/0000-0002-2980-9773
Ivo Ilvan Kerppers ${ }^{4}$

https://orcid.org/0000-0001-5745-2006

Aristides Machado-Rodrigues ${ }^{5}$

https://orcid.org/0000-0002-7169-8034

Luis Paulo Gomes Mascarenhas ${ }^{1 *}$

https://orcid.org/0000-0002-7762-2727

${ }^{1}$ Midwestern State University, Irati, Paraná, Brazil; ${ }^{2}$ State University of Londrina, Londrina, Paraná, Brazil; ${ }^{3}$ Midwestern State University, Department of Pharmacy, Guarapuava, Paraná, Brazil; ${ }^{4}$ Midwestern State University, Guarapuava, Paraná, Brazil; ${ }^{5}$ University of Coimbra, School of Education of Viseu, Polytechnic Institute of Viseu, Portugal;

Editor-in-Chief: Paulo Vitor Farago

Associate Editor: Paulo Vitor Farago

Received: 2021.06.21; Accepted: 2021.10.04.

*Correspondence: Imascarenhas@unicentro.br; Tel.: +55-42-3421-3000 (L.P.G.M.).

\section{HIGHLIGHTS}

- L-tryptophan and Nanoparticles in the motor and cognitive behavior in Alzheimer.

- L-tryptophan Nanoparticles it lowers anxiety and improves motor behavior in Alzheimer.

- Acute Effect of L-Tryptophan Nanoparticles on Alzheimer's Disease.

- Acute Effect of L-Tryptophan Nanoparticles in an Animal Model of Alzheimer's.

Abstract: Alzheimer's disease is the most common neurodegenerative disorder, with cognitive as well as behavioral manifestations. Also related to this pathology, is the decreased production and activation of some neurotransmitters, such as Serotonin, which is derived from the Tryptophan. Different methods to improve the effect and performance of some drugs have been studied including the Nanoparticles. The objective was to analyze the efficacy of L-tryptophan and L-tryptophan Nanoparticles in the acute response of motor and cognitive behavior in an Alzheimer's experimental model. Methods: 15 Wistar rats, divided into 3 groups $(n=$ 5): GC (Alzheimer's control group), GLt (L-tryptophan), and GN (Nanoparticles). They were treated for six consecutive days. Anxiety tests, spatial memory tests, aversive memory tests, and motor behavior tests were all performed during this study. In the analysis of anxiety, improvement was observed in both treatments, being that GN presented improvement in two variables: freezing $(79 \pm 18.8 ; 74.6 \pm 14.2)$ and TBF $(287.8 \pm 1.08$; $268 \pm 40.8)$. GLt only presented improvement in freezing (103.8 444.4$)$. In the spatial memory analysis, there 
were no significant differences in aversive memory and motor behavior during the treatments. During the Size Effect analysis treatments, it is possible to observe some differences both in anxiety and motor behavior, precisely where NG presented better results than GLt. Even in a short period of time, the nanoparticles demonstrated great benefits as a treatment method. Conclusion: the use of nanoparticles is an effective treatment against changes in motor and cognitive behavior caused by Alzheimer's, as it lowers anxiety and improves motor behavior.

Keywords: Alzheimer's disease; nanoparticles; tryptophan.

\section{INTRODUCTION}

Alzheimer's disease (AD) is the most common neurodegenerative pathology with cognitive and neuropsychiatric manifestations, defined by massive synaptic loss and neuronal degeneration in the brain regions responsible for cognitive functions, including the cerebral cortex, hippocampus, entorhinal cortex, and the ventral striatum $[1,2]$.

In addition, behavioral changes appear intensely in the early stages and can start with changes in the language, memory, judgment, temporo-spatial orientation and executive functions [3].

The formation of amyloid plaques and intraneural neurofibrillary tangles contribute to the degenerative process and are the most important characteristics in the advancement of AD [4]. Also having to do with the pathology is the decrease in the production and activation of some neurotransmitters responsible for brain activity such as serotonin (5-HT). Serotonin is derived from tryptophan, an essential amino acid, and is supplied by the normal dietary intake or degradation of proteins present in the body [5].

$5-\mathrm{HT}$ is found in various regions of the brain, mainly in the nuclei of the brainstem raphe, that contains bodies of serotonergic neurons, which synthesize, store and release 5-HT as a neurotransmitter [6].

Some drugs are used to treat $A D$, and despite their pharmacotherapeutic characteristics, they are still physiologically insufficient providing the cure and/or any clinical control over the disease [7], making it necessary to further studies with different drugs that could possibly be used in alternative treatments.

Different methods have been used in several different studies with the intention of improving the effectiveness of AD-specific drugs. Among these methods is that of Nanoparticles, which are designed to increase the bioavailability of the drugs, in turn, minimizing their side effects. In addition to this, Nanoparticles are highly stable, providing a long shelf life, high transport capacity, and the feasibility of incorporating hydrophilic and hydrophobic substances [8].

The aim of this study is to analyze the efficacy of L-tryptophan and Nanoparticles with L-tryptophan in the acute response of motor and cognitive behavior in experimental Alzheimer's models.

\section{MATERIAL AND METHODS}

The sample consisted of 15 male Wistar rats of the Rattus Norvegicus race, weighing between 200-250 grams, all around 2 months old, with food and water ad libitum throughout the study period. The rats were put in cages on a shelf in a room and then put through the light/dark cycle for 12 hours (lights on from 7 a.m. to 7 p.m.) at a temperature of $23 \pm 1^{\circ} \mathrm{C}$ regulated by a split $7000 \mathrm{BTU}$ 's air conditioning unit. This study was approved by the Ethics Committee on animal use - CEUA of the Midwestern State University under case 025/2016.

The animals were randomly divided into 3 groups as shown in table 1.

Table 1. Group divisions.

\begin{tabular}{cll}
\hline GROUPS $(\mathbf{n}=\mathbf{5})$ & \multicolumn{1}{c}{ DESCRIPTION } & \multicolumn{1}{c}{ INTERVENTION } \\
\hline CG & Induction of senile plaques & Without intervention \\
NG & Nanoparticles group with induction of senile plaques & Ingestion of L-Tryptophan \\
& & Nanoparticles \\
LtG & L-Tryptophan group with induction of senile plaques & Ingestion of L-Tryptophan \\
\hline
\end{tabular}




\section{Experimental Surgery}

The rats $(n=15)$ were anesthetized intra-abdominally with a solution at the proportion of $80 \mathrm{mg} / \mathrm{kg}$ of Ketamine Hydrochloride (Ketamine, $10 \mathrm{~mL}$ bottle) to $15 \mathrm{mg} / \mathrm{kg}$ of Xylasin Hydrochloride (Dopaser, $10 \mathrm{~mL}$ bottle) and then taken to an INSIGHT® stereotaxic instrument, where their heads were fixed by the temporal cliff and upper incisors. The coordinates used were: $A P=0.0 \mathrm{~mm}, \mathrm{ML}= \pm 1.8 \mathrm{~mm}$ and $\mathrm{DV}=4.0 \mathrm{~mm}$, respectively, using the bregma as a point of reference; the lambdoid and bregmatic sutures were held in the same horizontal plane. Next, 3 microliters of Beta-Amyloid Toxin ${ }_{1-42}$ were injected by means of a 10 microliter Halminton syringe, 0.02 microliters every minute, totaling 9 minutes of induction. All this was done using the coordinates of the Paxinos and Watson atlas, 1997. For analgesia, tramadol hydrochloride was used at a dose of $10 \mathrm{mg} / \mathrm{kg}$, every 12 hours, intraperitoneally for 7 (seven) days [9].

After induction of the senile plaque process and neuro-fibrillation, the rats rested for a period of 30 days so that the inflammatory and neurodegenerative processes of the hippocampal neurons could occur. One of the rats was euthanized in order to verify the presence of plaques and neurofibrils in the hippocampus, only after this verification did the other animals receive their respective treatment protocols.

\section{Treatments}

\section{L-Tryptophan nanoparticles and L-Tryptophan}

This treatment was done by gavaging the rats with $1.5 \mathrm{mg}$ of L-Tryptophan nanoparticles and LTryptophan for a period of six consecutive days at the same time every day.

\section{Obtaining the L-tryptophan nanoparticles}

The nanoparticles containing tryptophan were prepared by the evaporation emulsification method of the solvent, using a simple emulsion (O/A). Initially, $5.0 \mathrm{mg}$ of tryptophan was dissolved in the appropriate solvent and the polymer to obtain the nanostructured system (poly-epsiloncaprolactone, $50 \mathrm{mg}$ ) was dissolved in dichloromethane $(1000 \mu \mathrm{L})$, thereby forming the oily phase of the formulation. The oily phase was poured into the aqueous phase composed of $10 \mathrm{~mL}$ of $0.5 \%$ polyvinyl alcohol (PVA), which proceeded under sonication for 3 minutes at $60 \mathrm{~Hz}$. After sonication, the emulsion formed was evaporated on a rotary evaporator under negative pressure to remove the organic solvents. The nanoparticles formed were separated by centrifugation (15,000 rpm/30 minutes), and the precipitate was resuspended in water, followed by further centrifugation. The supernatant resulting from the two centrifugations was separated to be analyzed for tryptophan encapsulation efficiency. The nanoparticle precipitate was resuspended in 5\% sucrose and lyophilized for further storage. The final production of nanoparticles used was $90 \mathrm{mg}$. It was divided among the animals that received the dose of $1.5 \mathrm{mg}$, where the nanospheres had an approximate size of $171.6 \mathrm{~nm}$.

The polymer used to encapsulate the tryptophan was zein (corn protein) together with sodium caseinate (milk protein), which makes the compound more hydrophilic, triggering the release of the drug faster even if controlled, since tryptophan has hydrophobic characteristics with slower controlled release. Among all the analyzes of the quality control of nanoparticle production, only the Z potential was not done because it is an indirect measure, which reflects the electrical potential of the suspended particles.

\section{Anxiety}

The Elevated Plus Maze was used during the analysis of anxiety-related factors. It consisted of a crossshaped structure composed of two open arms perpendicular to two closed arms, with the whole structure raised $60 \mathrm{~cm}$ from the ground. The rat would be placed in the center of the labyrinth facing one of the open arms, where it could choose any of the four arms. Two of the arms were open, allowing the rat to see the ground. The other two arms were closed. The rats would prefer the closed arms but could explore the open arms too. They were only considered to be in one of the arms when they had all four members inside that same maze arm. Their behavior would be monitored for five minutes. After each session, the maze was cleaned with a solution of $50 \%$ ethanol in water to minimize the odor traces left by the previous test rat. Behaviors such as freezing, number of fecal cakes, and more time in the closed arms are related to a higher rate of anxiety [10]. All analyzes were done by an observer after DVR recording. 


\section{Spatial Memory}

The Morris Water Test Maze, or Aquatic Labyrinth was applied to evaluate the rat's ability to acquire spatial memory by observing the rat's latency as it tried to locate a platform that was submerged in a tank with of opaque water [11]. A circular glass fiber tank, $134.0 \mathrm{~cm}$ in diameter and $40.0 \mathrm{~cm}$ high, was used with a $15.0 \times 15.0 \mathrm{~cm}$ wide and $28.5 \mathrm{~cm}$ high square stainless-steel platform. This platform was located at the center of a $12 \mathrm{~m}^{2}$ room with an upper window on the south wall. The exercises and tests began at 8 o'clock in the morning. To begin the test, water was added to the tank until it was $2.0 \mathrm{~cm}$ above the platform. Then, the water was made opaque with the addition of corn starch. The test consisted of 2 days of training and a session of tests done 48 hours after the last day of training. In the training phase, the rats had 5 daily trials, with a maximum time of 54 seconds for each trial and 30-second intervals to find the platform located in the center of the tank. For each test the rats were released facing the tank wall, leaving from pseudo-random points. All analyzes were done by an observer after DVR recording.

\section{Aversive Memory}

Initially the rats were trained in the task of conditioned fear. Summarized, this task uses a training chamber (model MED-VFC2-SCT-R, Med Associates Inc., St. Albans, Vermont 05478), consisting of an aluminum box $(35 \times 35 \times 35 \mathrm{~cm})$ with a floor made of parallel stainless-steel bars spaced at $0.8 \mathrm{~mm}$ apart. This training box sat inside a larger, acoustically isolated box to attenuate the interference of external sounds.

The mnemonic performance was measured and expressed in the time that the rat remained in a state of paralysis ("freezing"). This behavior is associated as an index of fear in rats [12].

\section{Motor behavior}

To evaluate motor activity, the open field test (OF) was used. It is an apparatus that consists of a round arena (100 cm in diameter and $45 \mathrm{~cm}$ in height), with the floor divided into 9 quadrants. The rats were carefully placed in the center of the OF and allowed to explore it freely for $5 \mathrm{~min}$. Three motor parameters were registered: number of quadrants (the number of times all four legs of the rat crossed from one quadrant to another), stand frequency (the number of times the rats stood on their hind legs), number of fecal cakes and time of immobility (time in seconds that the animal remained immobile) [13]. The animals were carefully placed in the southwest position of the OF and allowed to freely explore the area for $5 \mathrm{~min}$. The OF was cleaned with a $5 \%$ water-ethanol solution before each rat's test to eliminate odors and substances left by the previous rats. This was done to prevent them from being induced to follow the same course as the previous rat. All analyzes were done by an observer after DVR recording.

\section{Statistical Analysis}

To analytically treat the data, the Shapiro-Wilk tests of normal distribution and the Levene tests of homogeneity of variances were initially performed. In situations where there was normality and homogeneity, the comparison between groups was done through factorial analysis (ANOVA factorial), with post hoc per pair and Bonferroni correction. In situations where there was no normality nor homogeneity, the comparison between groups was done through the Kruskal-Wallis non-parametric analysis of $\mathrm{H}$ variance, with post hoc by average posts. All tests adopted a $<0.05$ error probability to discover any significant difference between test results. The Size Effect analysis was used through the Cohen test with a confidence interval (Cl) of $95 \%$.

\section{RESULTS}

Table 2 shows the values related to the analysis of anxiety. In all groups, a significant statistical difference was observed in the freezing values after the induction of $A D$, in addition to an increase in the time the rats from the Nanoparticles group stayed in the closed arm of the maze. The decrease in freezing can be observed in the Nanoparticles and L-tryptophan groups $(p=0.001)$ demonstrating the beneficial effect of these treatments on anxiety. 
Table 2. Analysis of the variables of Anxiety.

\begin{tabular}{|c|c|c|c|c|c|}
\hline ANXIETY & & Freezing $^{\Omega}(\mathbf{s})$ & Grooming $^{\Omega}(\mathrm{n})$ & $\operatorname{TOA}^{\Omega}(s)$ & $\operatorname{TCA}^{\ddagger}(s)$ \\
\hline & pre induction & $3 \pm 3.46^{a}$ & $1.6 \pm 0.54$ & $11 \pm 8.06$ & $289 \pm 8.06$ \\
\hline \multirow[t]{3}{*}{ Alzheimer's } & post induction & $79.4 \pm 20.8$ & $2.4 \pm 1.14$ & $20.0 \pm 25.7$ & $279 \pm 25.7$ \\
\hline & pre induction & $3.6 \pm 4.9^{a}$ & $2.4 \pm 1.51$ & $51.4 \pm 41.9$ & $130.2 \pm 99.7^{a}$ \\
\hline & post induction & $79 \pm 18.8^{b}$ & $2.2 \pm 2.2$ & $4.0 \pm 8.9$ & $287,8 \pm 1,08^{b}$ \\
\hline \multirow[t]{3}{*}{ Nanoparticles } & post treatment & $74.6 \pm 14.2$ & $2.0 \pm 1.5$ & $30 \pm 41.4$ & $268 \pm 408$ \\
\hline & pre induction & $11.8 \pm 8.16^{a}$ & $0.6 \pm 0.8$ & $1.0 \pm 2.23$ & $286.4 \pm 11.9$ \\
\hline & post induction & $103.8 \pm 44.4^{b}$ & $0.4 \pm 0.54$ & $3.0 \pm 6.7$ & $287.2 \pm 14.8$ \\
\hline L- tryptophan & post treatment & $69.4 \pm 20.8$ & $1.0 \pm 1.0$ & $8.0 \pm 13$ & $289.6 \pm 17.3$ \\
\hline
\end{tabular}

$a=$ pre and post difference $(\leq 0.05) ; b=$ difference between post- induction and post- treatment $(\leq 0.05)$.; $¥=$ parametric (Anova), $\Omega=$ non-parametric (Krukal Wallis). TOA= time stayed in the open arm; TCA = time stayed in the closed arm.

Table 3 shows the values analyzed in relation to spatial memory, where there was significant statistical difference only in the Alzheimer group after senile plaque induction.

Table 3. Analysis of Spatial Memory.

\begin{tabular}{lll}
\hline & SPATIAL MEMORY & Latency $\mathbf{S}^{(\mathbf{s})}$ \\
\hline Alzheimer's & pre induction & $7.4 \pm 5.2^{\mathrm{a}}$ \\
Nanoparticles & post induction & $300 \pm 0.0$ \\
& pre induction & $49.8 \pm 39.9$ \\
& post induction & $9.4 \pm 6.6$ \\
L- tryptophan & post treatment & $6.2 \pm 2.7$ \\
& pre induction & $33.6 \pm 28.6$ \\
& post induction & $9.6 \pm 7.12$ \\
& post treatment & $11 \pm 6.9$ \\
\hline
\end{tabular}

$a=$ pre and post difference; $\Omega=$ non-parametric (Krukal Wallis), $(p \leq 0.05)$.

Table 4 shows the values related to aversive memory, which presented significant statistical difference only in the L-tryptophan group, with a decrease of freezing after AD induction.

Table 4. Analysis of Aversive Memory.

\begin{tabular}{llc} 
& AVERSIVE MEMORY & Freezing $\mathbf{g}^{\Omega}(\mathbf{s})$ \\
\hline Alzheimer's & pre induction & $9.6 \pm 5.0$ \\
Nanoparticles & post induction & $11 \pm 1.22$ \\
& pre induction & $12 \pm 6.2$ \\
& post induction & $8 \pm 2.5$ \\
L- tryptophan & post treatment & $5.8 \pm 1.7$ \\
& pre induction & $17.8 \pm 8.6^{\mathrm{a}}$ \\
& post induction & $4.2 \pm 4.9$ \\
& post treatment & $11.4 \pm 6.9$ \\
\hline
\end{tabular}

$\mathrm{a}=$ pre and post difference; $\mathrm{b}=$ difference between post induction and post tretment; $\Omega=$ non-parametric (Krukal Wallis), $(p \leq 0.05)$. 
Regarding motor behavior, the data in table 5 indicated that there was a significant difference in the pre and post induction variables in all groups that characterized the presence of AD. However, none of the treatments were statistically significant.

Table 5. Analysis of Motor Behavior.

\begin{tabular}{|c|c|c|c|c|c|c|c|c|c|}
\hline \multicolumn{2}{|c|}{ MOTOR BEHAVIOR } & \multirow{2}{*}{$\begin{array}{c}\begin{array}{c}\text { Stands } \\
\text { (n) }\end{array} \\
40 \pm 9.8^{\mathrm{a}}\end{array}$} & \multirow{2}{*}{$\begin{array}{c}\begin{array}{c}\text { Freezing } \\
\text { (s) }\end{array} \\
5.6 \pm 3.7^{\mathrm{a}}\end{array}$} & \multirow{2}{*}{ 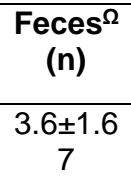 } & \multirow{2}{*}{$\begin{array}{c}\begin{array}{c}\text { Latency } \\
\text { (s) }\end{array} \\
2.8 \pm 1.92\end{array}$} & \multirow{2}{*}{$\begin{array}{c}\begin{array}{c}\text { Q1 } \\
\text { (n) }\end{array} \\
6.8 \pm 2.04^{a}\end{array}$} & \multirow{2}{*}{$\begin{array}{l}\begin{array}{l}\mathbf{Q 2}^{\mp} \\
\text { (n) }\end{array} \\
7 \pm 2.7^{\mathrm{a}}\end{array}$} & \multirow{2}{*}{$\begin{array}{c}\begin{array}{c}\mathbf{Q 3}^{¥} \\
\text { (n) }\end{array} \\
7.2 \pm 2.9^{a}\end{array}$} & \multirow{2}{*}{ 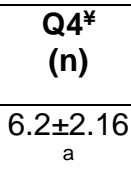 } \\
\hline Alzheimer's & $\begin{array}{l}\text { pre } \\
\text { induction }\end{array}$ & & & & & & & & \\
\hline & $\begin{array}{l}\text { post } \\
\text { induction }\end{array}$ & $7 \pm 2.4$ & $\begin{array}{c}138.8 \pm 39 \\
1\end{array}$ & $3.4 \pm 2.7$ & $35.8 \pm 58.4$ & $1.6 \pm 0.89$ & $1.6 \pm 1.8$ & $\begin{array}{c}1.6 \pm 1.8 \\
1\end{array}$ & $1.2 \pm 1.09$ \\
\hline \multirow[t]{3}{*}{$\begin{array}{l}\text { Nanoparticle } \\
\text { s }\end{array}$} & $\begin{array}{l}\text { pre } \\
\text { induction }\end{array}$ & $33.6 \pm 4.2^{\mathrm{a}}$ & $9,8 \pm 6.01^{\mathrm{a}}$ & $4.8 \pm 2.1$ & $9.8 \pm 4.5$ & $6.4 \pm 1.8^{\mathrm{a}}$ & $7.2 \pm 1.7^{\mathrm{a}}$ & $7.2 \pm 3.4^{\mathrm{a}}$ & $8 \pm 2.9^{a}$ \\
\hline & $\begin{array}{l}\text { post } \\
\text { induction }\end{array}$ & $10.6 \pm 4.3$ & $\begin{array}{c}102.6 \pm 17 \\
7\end{array}$ & $1.4 \pm 1.5$ & $4.8 \pm 4.7$ & $3 \pm 2.4$ & $3.4 \pm 2.3$ & $2.6 \pm 1.5$ & $2 \pm 1.7$ \\
\hline & $\begin{array}{l}\text { post } \\
\text { treatment }\end{array}$ & $12.8 \pm 1.3$ & $72.2 \pm 11.6$ & $0.8 \pm 0.4$ & $0 \pm 0$ & $2 \pm 1$ & $1.6 \pm 0.8$ & $1 \pm 0.7$ & $1.2 \pm 1$ \\
\hline \multirow[t]{3}{*}{ L- tryptophan } & $\begin{array}{l}\text { pre } \\
\text { induction }\end{array}$ & $33.4 \pm 8.3^{a}$ & $14.8 \pm 5.6^{a}$ & $4.8 \pm 1.3$ & $10.4 \pm 4.5$ & $7.6 \pm 2.4^{\mathrm{a}}$ & $5.6 \pm 2.1$ & $4 \pm 1.8$ & $6.6 \pm 2.4^{a}$ \\
\hline & $\begin{array}{l}\text { post } \\
\text { induction }\end{array}$ & $12.4 \pm 7.6$ & $\begin{array}{c}105.4 \pm 26 . \\
1\end{array}$ & $3.2 \pm 3.8$ & $18 \pm 11.5$ & $2.2 \pm 1.6$ & $2.6 \pm 0.8$ & $1.8 \pm 1$ & $2 \pm 1.2$ \\
\hline & $\begin{array}{l}\text { post } \\
\text { treatment }\end{array}$ & $7.2 \pm 4.08$ & $\begin{array}{c}115.6 \pm 69 \\
2\end{array}$ & $2.8 \pm 1.9$ & $16.2 \pm 18$ & $1.6 \pm 1.5$ & $1.4 \pm 0.5$ & $1.4 \pm 0.8$ & $1 \pm 0.7$ \\
\hline
\end{tabular}

$\mathrm{a}=$ pre and post difference; $¥=$ parametric (Anova), $\Omega=$ non-parametric (Krukal Wallis), ( $\leq 0.05)$. $Q=$ quadrant.

While there were no significant statistically differences, by means of the Size Effect described in table 6, it is possible to observe differences in relation to the treatments, and even with an average effect the Nanoparticles group presented better results in relation to treatment with L-tryptophan in motor behavior.

Table 6. Comparative analysis of the effects by sample size.

\begin{tabular}{|c|c|c|c|c|c|}
\hline \multicolumn{2}{|c|}{ Size Effect } & \multicolumn{2}{|c|}{ Nanoparticles } & \multicolumn{2}{|c|}{ L-tryptophan } \\
\hline & & d & $\mathbf{r}$ & d & $\mathbf{r}$ \\
\hline \multirow{3}{*}{ Anxiety } & $\begin{array}{l}\text { Freezing (s) } \\
\text { Grooming (n) }\end{array}$ & $\begin{array}{c}0.26 \\
0.1\end{array}$ & $\begin{array}{l}0.13 \\
0.05\end{array}$ & $\begin{array}{l}0.99 \\
-0.74\end{array}$ & $\begin{array}{c}0.44 \\
-0.34\end{array}$ \\
\hline & TOA (s) & -0.86 & -0.39 & -0.48 & -0.23 \\
\hline & TCA (s) & 0.66 & 0.31 & -0.14 & -0.07 \\
\hline Spatial Memory & Latency (s) & 0.63 & 0.3 & -0.19 & -0.09 \\
\hline \multirow[t]{4}{*}{ Aversive Memory } & Freezing (s) & 1 & $0.45^{\mathrm{t}}$ & -1.2 & -0.51 \\
\hline & Stands (n) & -0.69 & -0.32 & 0.85 & 0.39 \\
\hline & Freezing (s) & 2.03 & $0.71^{\mathrm{t}}$ & -0.19 & -0.09 \\
\hline & Feces $(n)$ & 0.54 & 0.26 & 0.13 & 0.06 \\
\hline \multirow[t]{5}{*}{ Motor Behavior } & Latency (s) & 1.44 & $0.58^{\ddagger}$ & 0.11 & 0.05 \\
\hline & Q1 (n) & 0.54 & 0.26 & 0.38 & 0.18 \\
\hline & Q2 (n) & 1 & $0.46^{\mathrm{t}}$ & 1.79 & $0.66^{\mathrm{t}}$ \\
\hline & Q3 (n) & 1.36 & $0.56^{\ddagger}$ & 0.46 & 0.21 \\
\hline & Q4 (n) & 0.56 & 0.26 & 1 & $0.45^{\mathrm{t}}$ \\
\hline
\end{tabular}


$d=$ average of difference; $r=$ size of the effect; $I C=95 \%$; $\mp=$ large effect $(\geq 0,80)$; $t=$ average effect $(0.40-0.70) ;{ }^{*}$ negative values=no effect. $\mathrm{TOA}=$ time in the open $\operatorname{arm} ; \mathrm{TCA}=$ time in the closed $\operatorname{arm} ; \mathrm{Q}=$ quadrant.

\section{DISCUSSION}

Regarding the analysis of anxiety, it can be said that even in an acute treatment evaluation, the nanoparticles showed a beneficial effect, since there was a decrease of two of the four variables (table 2). LTryptophan also had a positive effect through the decrease in the frequency of freezing after the treatment (Table 2). This shows the positive effects of L-Tryptophan as a precursor of serotonin to improve brain performance, since the plasmatic increase of tryptophan promotes diffusion of tryptophan to the brain and consequently stimulate the synthesis, the concentration, and the release of serotonin $[14,15]$. It was observed, therefore, that L-Tryptophan reduces anxiety and has its effect improved when administered in the form of nanoparticles.

The loss or decrease of spatial memory is a relevant feature in AD because of the progressive damage that affects the region of the temporal lobe, which is related to executive and memory functions [16]. None of the treatments performed in this study demonstrated efficacy in altering this, a result justifiable by the short time period of the treatment, or the influence of external environmental factors such as temperature, noise, or the luminosity of the environment [17]. In a study in 2017, after treatment with L-Tryptophan for 21 days, there was significant improvement in the spatial memory of their rats, differing from the present study, probably due to the longer treatment time compared to the six days that were used in this study [18].

Aversive memory in turn presented a difference only in relation to the AD induction protocol (table 4), where there was a decrease in the rat's paralysis, which indicated memory loss, an important feature of the disease [19]. The fact that there was no improvement after the treatments may be related to the final consolidation phase of this memory, recall, which depends on the time of reactivation of this memory to occur [20]. Once recall is extended, the memory can be extinguished, initiating a new phase of memory acquisition in the tests performed after the treatment, in consequence to the period in which the rats were not exposed to the stimuli.

In the Size Effect analysis, an improvement in motor behavior was observed when the nanoparticles method was used as treatment, where even with a small sample, its effectiveness was noted by observing action in the CNS. A main characteristic of AD are the motor and cognitive alterations, that cause limitations and complications in the overall clinical state of the disease's development. Thus, several different methods have been tested to discover any alternative treatments that improve the conditions of AD patients.

As reported in a study in 2012 there are many studies that apply nanoparticles to humans as a treatment for cancer [21], but the present study points to a new applicability of nanoparticles as a method of treatment for Alzheimer's. However, more studies in the area must be performed while considering longer treatment time and larger sample numbers.

\section{CONCLUSION}

Through the present study, the use of nanoparticles associated with L-tryptophan as a treatment for Alzheimer's has been deemed efficient in improving motor and cognitive behavioral due to the reduction of anxiety and better motor behavior patterns observed during the experiment

Funding: This research received no external funding.

Acknowledgments: Laboratory of Neuroanatomy and Neurophosiology for the space granted to carry out the research, and the Laboratory of Nanoscience for the production of Nanoparticles.

Conflicts of Interest: The authors declare no conflict of interest.

\section{REFERENCES}

1. López-Pousa A, Garre-Olmo J. Demencia: concepto, clasificación, epidemiología, aspectos socioeconómicos. Medicine. 2007;4921-7.

2. Selkoe DJ. Alzheimer's Disease: Genes, Proteins, and Therapy. Physiological Reviews. 2001;81:741-66.

3. Oliveira ARR de. O envelhecimento, a doença de Alzheimer e as contribuições do Programa de Enriquecimento Instrumental (PEI). Cuad neuropsicol. 2010;4:31-41.

4. Maccioni RB, Muñoz JP, Barbeito L. The Molecular Bases of Alzheimer's Disease and Other Neurodegenerative Disorders. Archives of Medical Research. 2001;32:367-81. 
5. Wurtman R, Fernstrom J. Control of brain monoaminesynthesis by diet and plasma amino acids. Am J Clin Nutr. 1975;28:638-47.

6. Katzung B, Julius D. Histamina, serotonina e os alcalóides do esporão do centeio. Farmacologia Básica \& Clínica. 8th ed. Rio de Janeiro: Guanabara Koogan; 2002. p. 233-56.

7. Souza N, Silva C, Silva V. Donepezilin the treatment of Alzheimer's disease. Rev estudos. 2014;41:755-66.

8. Yan F, Zhang C, Zheng Y, Mei L, Tang L, Song C, et al. The effect of poloxamer 188 on nanoparticle morphology, size, cancer cell uptake, and cytotoxicity. Nanomed.: Nanotechnol., Biol. Med. 2010;6:170-8.

9. Kamerman P, Koller A, Loram L. Postoperative Administration of the Analgesic Tramadol, but Not the Selective Cyclooxygenase-2 Inhibitor Parecoxib, Abolishes Postoperative Hyperalgesia in a New Model of Postoperative Pain in Rats. Pharmacology. 2007;80:244-8.

10. Drapier D, Bentueferrer D, Laviolle B, Millet B, Allain H, Bourin M, et al. Effects of acute fluoxetine, paroxetine and desipramine on rats tested on the elevated plus-maze. Behav. Brain Res. 2007;176:202-9.

11. Morris RGM, Garrud P, Rawlins JNP, O'Keefe J. Place navigation impaired in rats with hippocampal lesions. Nature. 1982;297:681-3.

12. Maren S, Phan KL, Liberzon I. The contextual brain: implications for fear conditioning, extinction and psychopathology. Nat Rev Neurosci. 2013;14:417-28.

13. Pietá Dias C, Martins de Lima MN, Presti-Torres J, Dornelles A, Garcia VA, Siciliani Scalco F, et al. Memantine reduces oxidative damage and enhances long-term recognition memory in aged rats. Neuroscience. 2007;146:1719-25.

14. Blomstrand E. A Role for Branched-Chain Amino Acids in Reducing Central Fatigue. J. Nutr. 2006;136:544S-547S.

15. Rossi L, Tirapegui J. Serotonina e neuromodulação alimentar. Nutrição em Pauta. 2005;13:36-40.

16. Gallucci Neto J, Tamelini MG, Forlenza OV. Diagnóstico diferencial das demências. Rev psiquiatr clín. 2005;32:119-30.

17. Andrade A, Pinto SC, Oliveira RS de. Animais de laboratório: criação e experimentação. Rio de Janeiro (RJ): Ed. Fiocruz; 2002.

18. Miri AL, Hosni AP, Gomes JC, Kerppers II, Pereira MC da S. Estudo do I-triptofano na depressão ocorrida pela doença de alzheimer em modelos experimentais. J Phys Educ [Internet]. 2017 [cited 2021 Oct 25];28. Available from: http://periodicos.uem.br/ojs/index.php/RevEducFis/article/view/33656

19. Zidan M, Arcoverde $C$, Araújo N de, Vasques P, Rios A, Laks J, et al. Alterações motoras e funcionais em diferentes estágios da doença de Alzheimer. Rev Psiq Clín. 2012;39:161-5.

20. Harris JA, Jones ML, Bailey GK, Westbrook RF. Contextual control over conditioned responding in an extinction paradigm. J. Exp. Psychol. Anim. Behav. Processes. 2000;26:174-85.

21. Oliveira L, Taveira E, Souza L, Marreto R, Lima E, Taveira S. Aplicações das Nanopartículas Lipídicas no Tratamento de Tumores Sólidos: Revisão de Literatura. Rev. Bras. Cancerol. 2012;58:695-701.

2021 by the authors. Submitted for possible open access publication under the terms and conditions of the Creative Commons Attribution (CC BY NC) license (https://creativecommons.org/licenses/by-nc/4.0/). 